\title{
Knowledge and practice of ventilator care bundle for preventing ventilator associated pneumonia by ICU nurses of tertiary care hospitals of Lahore
}

\author{
Zunaira Aziz, Samina Kausar, Saima Zahid, Samina Farooqi, Zara Aziz, Rana Altaf Ahmad
}

Correspondence: Zunaira Aziz, Institute of Nursing, University of Health Sciences, Lahore, 75500, Pakistan;

Phone: 0321-334832; E-mail: zunairasadaf26@gmail.com

\section{Abstract}

Background \& Objective: Ventilator associated pneumonia (VAP) is the most common nosocomial infection acquired by patients in an intensive care unit (ICU). However, there is scarce clinical data, particularly from Pakistani ICUs, regarding existing practices to prevent it. Prevention and control of VAP is said to be dependent on the nurses' knowledge and practices of ventilator care bundle (VCB), e.g., VAP prevention guidelines. We conducted this study to assess knowledge and practice of VCB by intensive care nurses of selected hospitals.

Methodology: A sample of 136 nurses, who met inclusion and exclusion criteria, were selected for this cross sectional, descriptive study. It was conducted in four tertiary care hospitals of Lahore over a period of 11 months extending, from Nov 2018 to Sep 2019. Non-probability purposive sampling technique was used. A modified knowledge-based questionnaire and a checklist was used to collect the data from the subjects. Based upon scoring system utilized, the knowledge level was categorized as; Excellent $=81-100 \%$, Good $=61-80 \%$, Average $=41-60 \%$, Poor $=<40 \%$. The practice of ventilator bundle was assessed as; satisfactory $=\geq$ $80 \%$ skills (used by Raulin D. Feria).

Statistical package for social sciences (SPSS) version-23 was used to analyze the data.

Results: The study findings revealed that nurses have poor knowledge of ventilator bundle with mean score of $37.5 \%$. The mean practice score demonstrated by ICU nurses was $60.8 \%$, which is also not satisfactory according to the criteria

Conclusion: On the basis of the findings of the current study, we conclude that the knowledge of the ICU nurses of the sample tertiary care hospitals of Lahore about the ventilator bundle is rated poor. Their practice of the bundle also does not meet the standard criteria. Corrective measures at an appropriate level are strongly recommended.

Key words: Critical Care Nurse; Knowledge; Practice; Ventilator associated pneumonia; Ventilator bundle

Citation: Aziz Z, Kausar S, Zahid S, Farooqi S, Aziz Z, Ahmad RA. Knowledge and practice of ventilator bundle by ICU nurses for preventing ventilator associated pneumonia. Anaesth. pain intensive care 2020;24(4):426-434.

Received: 21 July 2020, Reviewed: 30 July 2020, Revised: 3 August 2020, Accepted: 10 August 2020

\section{Introduction}

Increasing load of hospital acquired infections in ICUs demands for ventilator support for critically ill patients. ${ }^{1}$ Ventilator associated pneumonia (VAP) carries a mortality rate as high as $74 \% .^{2}$ The International Nosocomial Infection Control Consortium(INICC) reports the incidence of VAP is about 13.6/1000 mechanical ventilation days. ${ }^{3}$ Whereas, in Asian countries it is more common and ranges from 3.5 to 46 infections/1000 mechanical

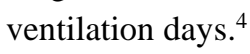

Ventilator associated pneumonia is the $2^{\text {nd }}$ most drastic nosocomial infection around the globe. ${ }^{5}$ Worldwide, Prevalence of ventilator associated pneumonia is $12.6 \%, 13.5 \%$ in US, $19.4 \%$ in Europe, $13.8 \%$ in Latin America and 16\% in South Asia. ${ }^{6}$ While in Pakistan VAP rate among children was observed as $17 \%$ and $30.5 \%$ in adults. ${ }^{7,8}$ 
Mechanical ventilation is said to be the major risk factor. ${ }^{9}$ While, some other factors are age $<1$ year, male gender, unplanned intubation, continuous sedation and most common pathogens are gram negative bacilli. ${ }^{10}$

There are several strategies that are implemented to address VAP and its complications but ventilator care bundle (VCB) carries utmost importance in this concern. ${ }^{11}$

International literature suggests that improved outcomes of care are dependent of nurses' knowledge and practices of $\mathrm{VCB} .{ }^{12}$ because they are in the best position to put the VCB interventions into practice as they are at bedside of intubated patients round the clock. ${ }^{13}$ But, it is observed that nurses' knowledge regarding VCB is inadequate and they are not complying with latest evidence based practices in ICUs (CDC Report, 2004). ${ }^{14}$

Ventilator associated pneumonia is an important intensive care related issue. It is equally important that the nurses working with ventilated patients be aware of the recommended practices to prevent and treat ventilator associated pneumonia. So, the present study was aimed at assessing ICU nurses' knowledge and practices of VCB in Lahore Pakistan.

\section{Methodology}

This survey-based, cross sectional, descriptive study was conducted from Nov 2018 to Sep 2019, after obtaining approval from the Research Committee of Institute of Nursing, and the Ethical Review Committee (ERC) of University of Health Sciences, Lahore. The data were collected from 136 female critical care nurses working in four tertiary care hospitals of Lahore, Pakistan i.e. Services Hospital, Jinnah Hospital, Shalamar Hospital and Sheikh Zaid Hospital. Nurses having one year or more working experience in medical/surgical adult ICU were included in the study using non-probability purposive sampling. Nurses with MSc (Nursing) qualification or with experience of working abroad were excluded from the study. Administrative permission was obtained from the heads of the selected hospitals.

A modified questionnaire was used. It comprised of three parts;
Part A consisted of nurse's demographic data, e.g., age, professional qualification and clinical experience.

Part B included fifteen multiple choice questions (MCQs) to assess knowledge (Annexure-II). Each question had four options, out of which one option was correct and given one mark, whereas the rest of three options were incorrect and marked zero (0). Based upon the scoring system utilized and overall mean score earned, the knowledge level was categorized into four categories (Box 1).

Part $\mathbf{C}$ included a check list to physically assess nurses' practices of VCB. The observational checklist was further divided into two sections; one was used to assess overall VAP bundle practices and the second was used to assess individual component practices of VAP bundle (Annexure-III).

\begin{tabular}{|c|c|}
\hline \multicolumn{2}{|c|}{$\begin{array}{l}\text { Box 1: Scoring system for the knowledge } \\
\text { level }\end{array}$} \\
\hline Score obtained & $\begin{array}{l}\text { Knowledge level } \\
\text { categories }\end{array}$ \\
\hline $81-100 \%$ & Excellent \\
\hline $61-80 \%$ & Good \\
\hline $41-60 \%$ & Average \\
\hline$<40 \%$ & Poor \\
\hline
\end{tabular}

The purpose and the nature of the study was explained and a written informed consent obtained from the participants who were involved in this study by a single investigator. Knowledge based questionnaire was distributed randomly among participants in two shifts (morning and evening). An observational checklist was used by researcher for assessing nursing practices of VCB. Researcher used covert approach to observe the participants because of Hawthorne effect.

Statistical Analysis: Data were analyzed using IBM SPSS statistics, version 23 (IBM $^{\mathrm{TM}}$ Corp. Armonk, USA). Demographic variables of study were age, qualification, working experience and hospital name. We analyzed the categorical values using Pearson's Chi-square test. Data were presented in the form of figures, tables, frequencies and percentages. Descriptive statistics were performed through Bar graphs and frequency distribution table. No sub group analysis is done in this study. 


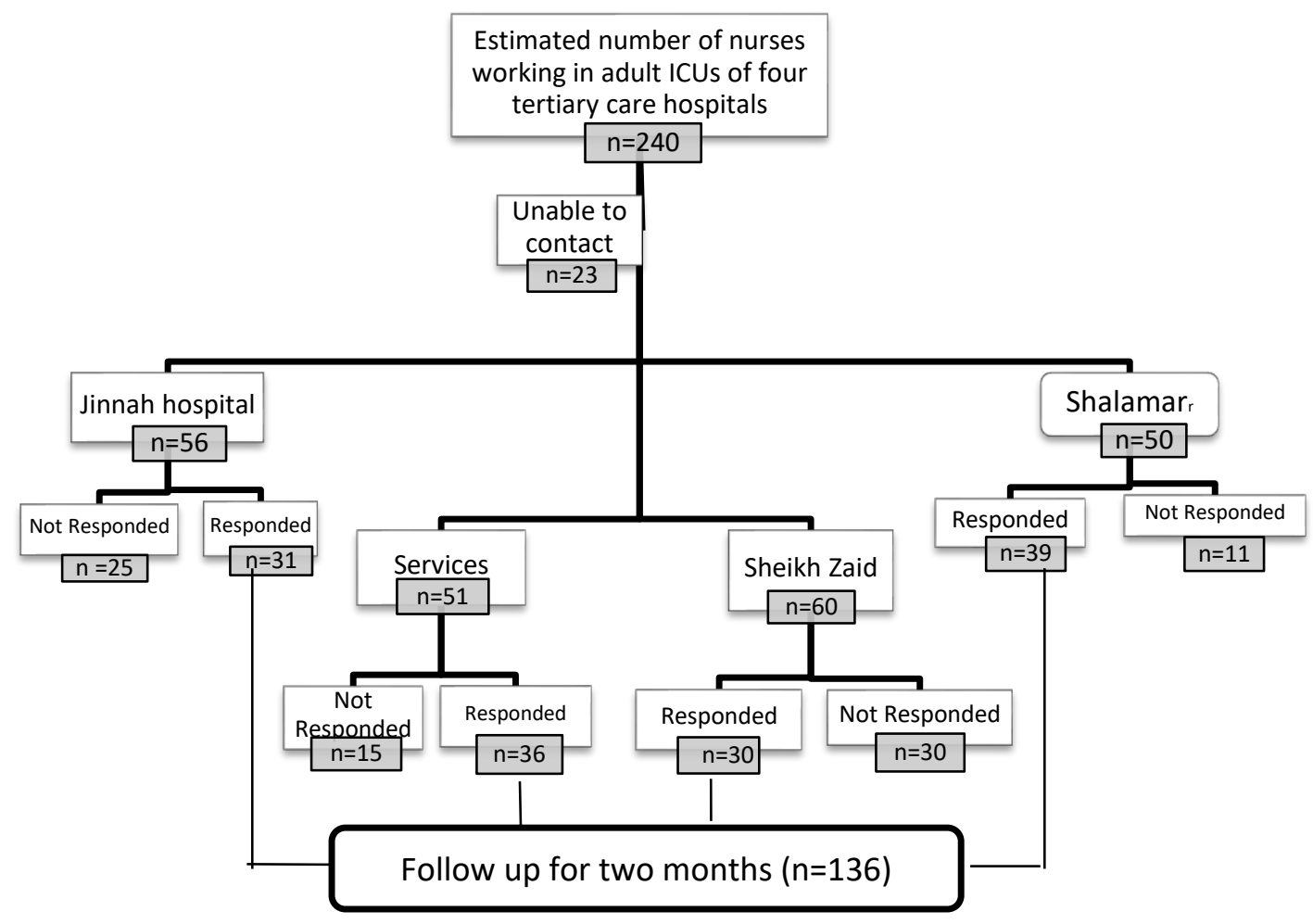

Figure 1: Scheme used in the study for sample recruitment

\section{Results}

Out of 240 nurses, 136 nurses were enrolled in the study, 81 did not respond and 23 were not accessible at the time of study (Figure 1). Table 1 presents the demographic frequency.

Table 2 describes Nurses knowledge of VCB. Table 3 tabulates the practice of main and individual VCB items by ICU nurses. Table 2 shows that majority of the participants were not aware of VAP bundle protocol and its significance in reducing VAP rates in ICUs as the mean knowledge score was observed $50.46 \%$ that is categorized as inadequate level of knowledge.

Table 3 shows that participant nurses scored $60.8 \%$ for practicing main items of VCB which is not satisfactory score according to the criteria

Table 4 shows that on an average, nursing practices of individual bundle items were also substandard (average score $<80 \%$ ). Only two components in oral care were meeting practice standard.

\section{Discussion}

The findings of the current study revealed that nurses working in ICU of four tertiary care hospitals of Lahore possessed poor knowledge and demonstrated substandard practices of VCB. Our findings are in line with a study documenting that nurses were deficit in VCB knowledge as majority of nurses had never heard of the term VCB. ${ }^{15}$

A quantitative cross-sectional study was conducted in Australia to explore Australian intensive care nurses' knowledge of ventilator-associated pneumonia and evidence-based guidelines. The study findings indicated that nurses lack knowledge of evidencebased guidelines for the prevention of ventilatorassociated pneumonia. ${ }^{16}$ 
Table 1: Demographic data

\begin{tabular}{lcccccc}
\hline \multicolumn{1}{c}{ Variables } & $\begin{array}{c}\text { Jinnah } \\
\mathbf{N}(\%)\end{array}$ & $\begin{array}{c}\text { Services } \mathbf{N} \\
(\%)\end{array}$ & $\begin{array}{c}\text { Shalamar } \\
\mathbf{N}(\%)\end{array}$ & $\begin{array}{c}\text { Sheikh Zaid N } \\
(\%)\end{array}$ & $\begin{array}{c}\text { Total } \\
\mathbf{N}(\%)\end{array}$ \\
\hline Participants & $31(23 \%)$ & $36(26 \%)$ & $30(22 \%)$ & $39(29 \%)$ & $136(100 \%)$ \\
\hline $20-30 \mathrm{y}$ & \multicolumn{2}{c}{ Age } & & & \\
\hline $31-40 \mathrm{y}$ & 13 & 12 & 9 & 11 & $45(33.1)$ \\
\hline $41-50 \mathrm{y}$ & 10 & 10 & 17 & 16 & $53(38.97)$ \\
\hline Above $50 \mathrm{y}$ & 6 & 9 & 3 & 10 & $28(20.58)$ \\
\hline & 2 & 5 & 1 & 2 & $10(7.35)$ \\
\hline Nursing Diploma & 15 & 18 & 11 & 19 & $63(46.32)$ \\
\hline Generic BSN & 8 & 7 & 6 & 9 & $30(22.05)$ \\
\hline Post-RN BSN & 6 & 7 & 9 & 7 & $29(21.32)$ \\
\hline Other Spec. & 2 & 4 & 4 & 4 & $14(10.29)$ \\
\hline & & Qxperience & & & \\
\hline $1-5 \mathrm{y}$ & 14 & 13 & 11 & 17 & $55(40.44)$ \\
\hline $6-10 \mathrm{y}$ & 10 & 11 & 10 & 10 & $41(30.14)$ \\
\hline $11-15 \mathrm{y}$ & 4 & 8 & 6 & 7 & $25(18.38)$ \\
\hline$>15 \mathrm{y}$ & 3 & 4 & 3 & 5 & $15(11.02)$ \\
\hline
\end{tabular}

Table 2: ICU nurses knowledge of VCB

\begin{tabular}{|c|c|c|c|c|}
\hline No. & Knowledge based Questions & Correct & Incorrect & $\begin{array}{c}\text { Not } \\
\text { Respond } \\
\text { ed }\end{array}$ \\
\hline 1 & $\begin{array}{l}\text { VCB is; } \\
\text { 1) A checklist used as a protocol of care for mechanically } \\
\text { ventilated patients. } \\
\text { 2) Guidelines used to reduce the risk of atelectasis } \\
\text { 3) Interventions to treat malignancies of lungs } \\
\text { 4) I do not know. }\end{array}$ & $13 \%$ & $79 \%$ & $8 \%$ \\
\hline 2 & $\begin{array}{l}\text { Non- Compliance to VCB tends to be associated with; } \\
\text { 1) Decreased risk of VAP } \\
\text { 2) High mortality in mechanically ventilated patients. } \\
\text { 3) Reduced morbidity in in mechanically ventilated patients. } \\
\text { 4) D. I don't know }\end{array}$ & $79 \%$ & $18 \%$ & $3 \%$ \\
\hline 3 & $\begin{array}{l}\text { Which component is not included in the VCB for the } \\
\text { prevention of VAP? } \\
\text { 1) Oral Care } \\
\text { 2) Head of bed elevation. } \\
\text { 3) Daily sedation vacation. } \\
\text { 4) Administration of antibiotics. }\end{array}$ & $16 \%$ & $84 \%$ & --- \\
\hline 4 & $\begin{array}{l}\text { VAP would occur in patients who are on mechanical } \\
\text { ventilation for; } \\
\text { a) } 6 \text { hours. } \\
\text { b) } 12 \text { hours. } \\
\text { c) } 24 \text { hours. } \\
\text { d) } 48 \text { hours. }\end{array}$ & $46 \%$ & $54 \%$ & --- \\
\hline 5 & $\begin{array}{l}\text { Which is the recommended position for mechanically } \\
\text { ventilated patient for the prevention of VAP? } \\
\text { a) Supine position. } \\
\text { b) Semi recumbent position. }\end{array}$ & $71 \%$ & $26 \%$ & $3 \%$ \\
\hline
\end{tabular}




\begin{tabular}{|c|c|c|c|c|}
\hline & \begin{tabular}{|l|l|} 
c) Prone position. \\
d) Side lying position.
\end{tabular} & & & \\
\hline 6 & $\begin{array}{l}\text { Head side of the bed should be elevated at? } \\
\text { a) } 0-15 \text { degree } \\
\text { b) } 15-30 \text { degrees. } \\
\text { c) } 30-45 \text { degrees. } \\
\text { d) I do not know. }\end{array}$ & $60 \%$ & $40 \%$ & --- \\
\hline 7 & $\begin{array}{l}\text { What is the effect of kinetic beds for the prevention of } \\
\text { VAP reduces the risk for VAP? } \\
\text { a) Increases the risk for VAP. } \\
\text { b) Reduces the risk for VAP. } \\
\text { c) No effect. } \\
\text { d) I don't know. }\end{array}$ & $47 \%$ & $51 \%$ & $2 \%$ \\
\hline 8 & $\begin{array}{l}\text { Which route is best recommended when intubating a } \\
\text { patient? } \\
\text { a) Oral rout } \\
\text { b) Nasal rout } \\
\text { c) Both routes are recommended } \\
\text { d) I do not know }\end{array}$ & $43 \%$ & $57 \%$ & --- \\
\hline 9 & $\begin{array}{l}\text { Evidence based guidelines for preventing VAP } \\
\text { recommended changing ventilator circuits how } \\
\text { frequently? } \\
\text { a) Every } 48 \text { hours } \\
\text { b) Every } 72 \text { hours } \\
\text { a) Every week } \\
\text { b) Every new patient }\end{array}$ & $65 \%$ & $35 \%$ & --- \\
\hline 10 & $\begin{array}{l}\text { A nurse caring a ventilated patient is required to wash } \\
\text { hands? } \\
\text { a) Before oral and ETT suctioning } \\
\text { b) After oral and ETT suctioning } \\
\text { c) Before and after oral / ETT suctioning } \\
\text { d) d. I don't know. }\end{array}$ & $44 \%$ & $56 \%$ & --- \\
\hline 11 & $\begin{array}{l}\text { It is recommended to perform oral care by using a swab } \\
\text { moistened with chlorhexidine } 1 \% \text {; } \\
\text { a) Once in a shift } \\
\text { b) Every } 4 \text { to } 6 \text { hours and whenever necessary } \\
\text { c) Twice daily } \\
\text { d) I do not know. }\end{array}$ & $56 \%$ & $44 \%$ & --- \\
\hline 12 & $\begin{array}{l}\text { One of the components of VCB is; } \\
\text { a) Chest Physiotherapy } \\
\text { b) Sedation Interruption } \\
\text { c) Daily ventilator circuit changes } \\
\text { d) I do not know. }\end{array}$ & $43 \%$ & $57 \%$ & --- \\
\hline 13 & $\begin{array}{l}\text { Early weaning; } \\
\text { a) Reduces the risk for VAP. } \\
\text { b) Increases the risk for VAP } \\
\text { c) Early weaning do not influence the risk for VAP } \\
\text { d) I don't know }\end{array}$ & $59 \%$ & $38 \%$ & $3 \%$ \\
\hline 14 & $\begin{array}{l}\text { What is the role of respiratory physiotherapy for } \\
\text { preventing VAP? } \\
\text { a) Highly recommended } \\
\text { b) Can be recommended. } \\
\text { c) There is no evidence of efficacy. } \\
\text { d) I don't know }\end{array}$ & $41 \%$ & $59 \%$ & --- \\
\hline 15 & $\begin{array}{l}\text { Contraindication for DVT prophylaxis include; } \\
\text { a) Thrombocytopenia (HIIT) } \\
\text { b) Active bleeding (GI bleed) } \\
\text { c) Presumed or confirmed clot in lower extremity } \\
\text { d) All of above }\end{array}$ & $74 \%$ & $26 \%$ & --- \\
\hline
\end{tabular}


Table 3: Observation checklist of main bundle Items

\begin{tabular}{l|l}
\hline \multicolumn{1}{c}{ Checklist items in practice of individual bundle items } & Yes \\
\hline A. Elevation of the Head of Bed & $67 \%$ \\
\hline Do the nurse elevate the head of the bed to 30-45? & $53 \%$ \\
\hline $\begin{array}{l}\text { Is she considers any contraindication(s) to elevating head of bed 30 degrees for mechanically } \\
\text { ventilated patient? }\end{array}$ & $46 \%$ \\
\hline B. Oral care with 1\% chlorohexidine & $77 \%$ \\
\hline Position a patient in a semi recumbent & $80 \%$ \\
\hline Hand washing before oral care & $70 \%$ \\
\hline Apply clean gloves and rinse mouth with a clean swab & $80 \%$ \\
\hline $\begin{array}{l}\text { Provide oral care with chlorhexidine 1\% according to hospital policy for mechanically } \\
\text { ventilated patients }\end{array}$ & $46 \%$ \\
\hline Clean equipment and return it to its proper place & $59 \%$ \\
\hline $\begin{array}{l}\text { C. Sedation interruption Protocol } \\
\text { Is the Implementation of daily sedation vacations based on the hospital's policy? }\end{array}$ & $31 \%$ \\
\hline $\begin{array}{l}\text { Does the nurse provide daily sedation vacations to mechanically ventilated patients according } \\
\text { to policy? }\end{array}$ & $63 \%$ \\
\hline Does the nurse provide spontaneous breathing trials as ordered by doctor? & $33 \%$ \\
\hline D. Peptic ulcer prophylaxis & $67 \%$ \\
\hline Does the nurse provide peptic ulcer prophylaxis as ordered by doctor? & $79 \%$ \\
\hline Is the implementation of peptic ulcer prophylaxis based on the hospital's policy? & \\
\hline E. Deep vein thrombosis prophylaxis & \\
\hline Does the nurse provide DVT prophylaxis as ordered by doctor? & Is there a contraindication(s) to deep vein thrombosis prophylaxis for mechanically ventilated \\
\hline patients? &
\end{tabular}

Table 4: Nursing practices of bundle items

\begin{tabular}{|c|c|}
\hline Practice of VCB items & $\begin{array}{l}\text { Observed } \\
\mathrm{N}(\%)\end{array}$ \\
\hline $\begin{array}{l}\text { 1. Elevate head of the bed } 30-45 \text { unless } \\
\text { contraindicated. }\end{array}$ & $91(66.9)$ \\
\hline $\begin{array}{l}\text { 2. Oral care using oral care kit (Chlorhexidine } 1 \% \\
\text { solution) }\end{array}$ & $96(70.5)$ \\
\hline 3. Use of appropriate sedation interruption protocol & $51(37.5)$ \\
\hline $\begin{array}{l}\text { 4. Gl prophylaxis and avoidance of abdominal } \\
\text { distention. }\end{array}$ & $85(62.5)$ \\
\hline 5. Carries out orders for DVT prophylaxis. & $91(66.9)$ \\
\hline Average Score & $60.8 \%$ \\
\hline
\end{tabular}

that the nurses' level of knowledge regarding VAP prevention guidelines was inadequate. ${ }^{19}$

Conversely, a study conducted in Spain has revealed that nurses' knowledge about VAP preventive measures was good. The results displayed good baseline knowledge of preventive measures. Likewise, results of some other studies revealed good level of knowledge and practices of VCB among nurses. ${ }^{20.21}$
There is increasing concern that nurses do not receive sufficient education in their undergraduate courses on VAP-prevention guidelines that's why they demonstrate inadequate knowledge and substandard practices. ${ }^{17}$ Theory practice gap presents dearth in adherence to VCB as another study results showed poor nurses knowledge and sub-standard practices of VCB. ${ }^{18}$

Similarly, another cross-sectional study was conducted in Iran and the results of the study revealed
As for VAP bundle practices, our study findings are congruent with studies documenting unsatisfactory practices of intensive care nurses as they were not using evidence based guidelines for patients on mechanical ventilation. ${ }^{22}$

On assessment of individual component of bundle care that come under nursing sphere of practice i.e. head of 


\section{Annexure-l: Questionnaire for assessing ICU nurses knowledge and practices of VCB for}

\section{preventing ventilator associated pneumonia}

\section{Part B: ICU nurses knowledge of VCB:}

Circle the correct choice

1. VCB is:
a. A checklist used as a protocol of care for mechanically ventilated patients.
b. guidelines used to reduce the risk of atelectasis
c. interventions to treat malignancies of lungs
d. I do not know.

2. Non-Compliance to VCB is associated with:
a. decreased risk of VAP
b. high mortality in mechanically ventilated patients.
c. Reduced morbidity in in mechanically ventilated patients.
d. I don't know

3) Which component is not included in the VCB for the prevention of VAP?
a. Oral Care
b. Head of bed elevation.
c. Daily sedation vacation.
d. Administration of antibiotics.

4. VAP would occur in patients who have received mechanical ventilation for:
a. 6 hours.
b. 12 hours.
c. 24 hours.
d. 48 hours.

5. Which is the recommended position for a ventilator patient for the prevention of VAP?
a. Supine position.
b. Semi recumbent position.
c. Prone position.
d. Side lying position.

6. Head of the bed elevation should be ranging from
a. $0-15$ degree
b. 15-30 degrees.
c. 30-45 degrees.
d. I do not know.

7. What is the effect of kinetic beds for the prevention of VAP?
a. Increases the risk for VAP.
b. Reduces the risk for VAP.
c. No effect.
d. I don't know.

8. Which route is best recommended when intubating a patient?
a. Oral intubation is recommended
b. Nasal intubation is recommended
c. Both routes of intubation are recommended
d. I do not know

9. Evidence-based guidelines for preventing VAP recommend changing ventilator circuits how frequently?
a. Every 48 hours
b. Every 72 hours
c. Every week
d. Every new patient

10. A nurse caring a ventilated patient is required to wash hands
a. Before oral and ETT suctioning
b. After oral and ETT suctioning
c. Before and after oral / ETT suctioning
d. I don't know.

11. It is recommended to perform Oral care by using a swab moistened with Chlorhexidine $1 \%$ ?
a. once in a shift
b. every 4 to 6 hours and whenever necessary
c. twice daily
d. I do not know.

12. One of the components of VCB is:
a. Chest Physiotherapy
b. Sedation Interruption
c. Daily ventilator circuit changes
d. I do not know.

13. Early weaning
a. Early weaning reduce the risk for VAP
b. Early weaning increase the risk for VAP
c. Early weaning do not influence the risk for VAP
d. I don't know

14. What is your opinion regarding respiratory physiotherapy for the prevention of VAP?
a. Highly recommended
b. Can be recommended
c. There is no evidence of efficacy.
d. I don't know.

15. Contraindications for DVT prophylaxis include:
a. Thrombocytopenia (HIIT)
b. Active bleeding (Gl bleed)
c. Presumed or confirmed clot in lower extremity
d. all of above 
bed elevation and oral care, majority of the ICU nurses in current study were confined with poor practices as observed mean score for head of bed elevation was $66.9 \%$ indicating low level of practices. Similar findings were presented in a study conducted in Riyadh showing that HOB elevation and sedation vacation bundle elements were the most deficient nursing interventions. ${ }^{23}$

As for oral care, participants' nurses in current study were also not complying with standard protocols i.e. swabbing the mouth with Chlorhexidine solution after every 2 to 4 hours. The results of current study are comparable with the findings identified by a study that nurses had never used Chlorhexidine solution for mouth wash and they were also not aware of the all recommended protocols for oral care ${ }^{24}$

In contrast, the findings of two other studies showed that health professionals possessed an adequate level of knowledge and excellent practices of vent bundle. ${ }^{25}$ Another study was piloted on 120 ICU nurses in Isfahan. The study findings revealed that the participants' practice was relatively acceptable as nurses were implementing basic components of $\mathrm{VCB}$ interventions. However, the authors of the study suggested that written protocol for VAP prevention and the existence of a monitoring systems in ICUs is also required for better patients outcomes. ${ }^{26}$

It is also concluded from a previous study that ICU nurses with more experience and proper intensive Care units training had better practices of VAP prevention. ${ }^{27}$

The current study has identified deficiencies in practice that are mostly similar to findings of above mentioned studies. The possible reasons of this may be due to a lack of knowledge, poor self-efficacy, timerelated barriers and inadequate delegation of responsibilities in extubation situations. For example, in our context majority of nurses are not doing spontaneous breathing trials of the patients because they are not allowed to do so. Also, knowledge of recommendations does not necessarily reflect practice. Nurses may provide oral care to the patient without knowing this is a guideline. Overall, the findings of this study complement the findings of other previous studies conducted in similar domains.

\section{Conclusion}

On the basis of the findings generated from the current study, we conclude that the VAP preventive strategies are being applied only partially by majority of the nurses, and their practices do not meet standard criteria. Their knowledge of the topic under study was also rated poor. So, continuous nursing education (CNE) programs are need of the hour in order to enhance nurses' knowledge and to keep them aware of the current evidence-based practices.

\section{Limitations of the study}

The cost of the study exceeded from the estimated one. Data collection took more time than expected. Non random sampling technique was used for study so that the findings of research cannot be generalized to a larger population.

\section{Conflict of interest}

None declared by the authors

\section{Authors' contribution}

ZA: Concept, conduction of the study work, manuscript writing

SK: Supervision, data analysis, manuscript editing

SZ: Data analysis, manuscript editing

SF, ZA, RA: Manuscript editing

\section{References}

1. Marra A, Ely EW, Pandharipande PP, Patel MB. The ABCDEF Bundle in Critical Care. Crit Care Clin. 2017;33(2):225-243. [PubMed] [Free full text] DOI: $10.1016 /$ j.ccc.2016.12.005

2. Kapoor J. A descriptive study to assess the knowledge and practice of intensive care nurses on prevention of ventilatorassociated pneumonia (VAP) among patients admitted in critical care units of Government Medical College Hospitals, Jammu (J\&K). Nat J Multidis Res Dev 2017;2(3):358-360

3. Rosenthal VD, Maki DG, Jamulitrat S, Medeiros EA, Todi SK, Gomez DY, et al. International nosocomial infection control consortium (INICC) report, data summary for 20032008, issued June 2009. Am J Infect Control. 2010;38(2):95104.e2. [PubMed] DOI:10.1016/j.ajic.2009.12.004

4. Mathai AS, Phillips A, Isaac R. Ventilator-associated pneumonia: A persistent healthcare problem in Indian Intensive Care Units! Lung India. 2016;33(5):512 [PubMed] [Free full text] DOI: 10.4103/0970-2113.188971 
5. Riaz $Q$, Ali SA. Implementation of ventilator bundle in pediatric intensive care unit of a developingcountry.J Coll Physicians Surg Pak. 2017;27(5):316-318 [PubMed]

6. Kollef MH, Chastre J, Fagon J-Y, François B, Niederman MS, Rello J, et al. Global prospective epidemiologic and surveillance study of ventilator-associated pneumonia due to Pseudomonas aeruginosa. J Crit Care Med. 2014;42(10):2178-87 [PubMed] DOI: $10.1097 / \mathrm{CCM} .0000000000000510$

7. Hamid MH, Malik MA, Masood J, Zia A, Ahmad TM. Ventilator-associated pneumonia in children. J Coll Physicians Surg Pak. 2012;22(3):155-8 [PubMed] [Free full text]

8. Kumar A, Ghauri MI, Razzaque S, Jamali A, Mohammad JS. Ventilator associated pneumonia; prevalence and microbial patterns. Pak. j. chest med. 2015;20(2) [Free full text]

9. Wałaszek M, Kosiarska A, Gniadek A, Kołpa M, Wolak Z, Dobroś $W$, et al. The risk factors for hospital-acquired pneumonia in the Intensive Care Unit. Przegl Epidemiol. 2016;70(1):15-20 [PubMed]

10. Brotfain E, Borer A, Koyfman L, Saidel-Odes L, Frenkel A, Gruenbaum SE, et al. Multidrug resistance acinetobacter bacteremia secondary to ventilator-associated pneumonia: risk factors and outcome. J Intensive Care Med. 2017;32(9):528-34 DOI: $\underline{10.1177 / 0885066616632193}$

[PubMed]

11. Kanafani ZA, El Zakhem A, Zahreddine N, Ahmadieh R, Kanj SS. Ten-year surveillance study of ventilator-associated pneumonia at a tertiary care center in Lebanon. J Infect Public Health. 2019;12(4):492-495 [PubMed] DOI: 10.1016/j.jiph.2019.01.057

12. Banjar A, Felemban M, Dhafar K, Gazzaz Z, Al Harthi B, Baig $M$, et al. Surveillance of preventive measures for ventilator associated pneumonia (VAP) and its rate in Makkah Region hospitals, Saudi Arabia. Turk J Med Sci. 2017;47(1):211-6 [PubMed] [Free full text] DOI: $10.3906 / \mathrm{sag}-1510-105$

13. Mogyoródi B, Dunai E, Gal J, Ivanyi Z. Ventilator-associated pneumonia and the importance of education of ICU nurses on prevention-Preliminary results. Interv Med Appl Sci. 2016;8(4):147-51 [PubMed] [Free full text] DOI: 10.1556/1646.8.2016.4.9

14. UC Irvine Seminar Papers and Posters. Braun SE. The Effects of Staff Education on Ventilator-Associated Pneumonia in the Intensive Care Unit: A Literature Review. Int J Nurs Educ Scholarsh. 2019. Available from https://escholarship.org/uc/item/9g86w925 (Accessed on 6 July 2020)

15. Saunders $\mathrm{H}$. Translating knowledge into best practice care bundles: A pragmatic strategy for EBP implementation via moving postprocedural pain management nursing guidelines into clinical practice. J Clin Nurs. 2015;24(13-14):203551[PubMed] DOI: 10.1111/jocn.12812

16. Madhuvu A, Endacott R, Plummer V, Morphet J. Nurses' knowledge, experience and self-reported adherence to evidence-based guidelines for prevention of ventilatorassociated events: A national online survey. Intensive Crit Care Nurs. 2020:102827 [PubMed] DOI: 10.1016/j.iccn.2020.102827
17. Jansson MM, Syrjälä HP, Talman K, Meriläinen MH, AlaKokko TI. Critical care nurses' knowledge of, adherence to, and barriers toward institution-specific ventilator bundle. Am J Infect Control 2018;46(9):1051-6 [PubMed] DOI: 10.1016/j.ajic.2018.02.004

18. Alja'afreh MA, Mosleh SM, Habashneh SS. Nurses' perception and attitudes towards oral care practices for mechanically ventilated patients. Saudi Med J. 2018;39(4):379-385 [PubMed] [Free full text] DOI: 10.15537/smj.2018.4.21749

19. Yeganeh M, Yekta H, Farmanbar R, Khalili M, Khaleghdoost T, Atrkar Roushan Z. Knowledge of evidence-based guidelines in ventilator-associated pneumonia prevention. $J$ Evid Based Med 2019;12(1):16-21 [PubMed] DOI: 10.1111/jebm. 12188

20. Jam R, Mesquida J, Hernández Ó, Sandalinas I, Turégano C, Carrillo E, et al. Nursing workload and compliance with non-pharmacological measures to prevent ventilatorassociated pneumonia: a multicentre study. Nurs Crit Care. 2018;23(6):291-8 [PubMed] DOI:10.1111/nicc.12380

21. Ghimire S, Neupane S. Knowledge regarding prevention of ventilator associated pneumonia among nurses in a tertiary hospital, Rupandehi, Nepal. J Univers Coll Med Sci. 2018:6(1):27-31 [Free full text] DOI: 10.3126/jucms.v6i1.21721

22. Aeen FB, Zolfaghari M, Noghabi AAA, Mehran A. Nurses' Performance in Prevention of Ventilator associated Pneumonia. Iran J Nurs Midwifery Res. 2013;19(3):17-27 [ Free full text]

23. Marini AL, Khan R, Mundekkadan S. Multifaceted bundle interventions shown effective in reducing VAP rates in our multidisciplinary ICUs. BMJ Open Qual. 2016;5(1):u205566. w2278 [PubMed] [Free full text] DOI: 10.1136/bmjquality.u205566.w2278

24. Rumagihwa L, Bhengu BR. Oral care practices of nurses on ventilated patients in Kigali Intensive Care Unit. Rwanda J Res Health Sci. 2019;2(2):154-9 [Free full text] DOI: 10.4314/rimhs.v2i2.11

25. Usman Shah HB, Atif I, Rashid F, Zulfiqar H, Mian K, Sarfraz $\mathrm{M}$, et al. Knowledge and practices of critical care health professionals related to ventilator associated pneumonia in tertiary care hospitals of Islamabad and Rawalpindi. J Pak Med Assoc. 2017;67(11):1714-8 [PubMed] [Free full text]

26. Tabaeian SM, Yazdannik A, Abbasi S. Compliance with the standards for prevention of ventilator-associated pneumonia by nurses in the intensive care units. Iran J Nurs Midwifery Res. 2017;22(1):31-36 [PubMed] [Free full text] DOI: $10.4103 / 1735-9066.202073$

27. Feria R. Ventilator Associated Pneumonia (VAP): Bundle Prevention Strategies in the Pediatric Intensive Care Unit. [Internet] Available from https://sigma.nursingrepository.org/bitstream/handle/10755/ 623555/RaulinFeriaEBPPaper.pdf?sequence=2\&isAllowed =y (Accessed on 7 July 2020) 